\title{
Alteridade em cena
}

\section{Resumo}

O objetivo é examinar uma das modalidades mais frequentes de contrapartida social propostas por coletivos apoiados pela municipalidade de São Paulo - o oferecimento de oficinas teatrais - analisando as relações entre seus responsáveis e os indivíduos por elas beneficiados. Tal exame sugere como oportuna a caracterização de uma ação especificamente artística, em paralelo à já reconhecida noção de ação cultural.

Palavras-chave: oficina teatral - Programa Municipal de Fomento ao Teatro - ação artística - teatro de grupo

Um recorte significativo em meio às múltiplas experiências de ação cultural em curso na cidade de São Paulo pode ser obtido a partir do exame das modalidades de contrapartida social propostas pelo Programa Municipal de Fomento ao Teatro.

É bem conhecido o fato de que os projetos provenientes dos grupos submetidos à seleção devem se comprometer a incluir práticas e operações de algum modo vinculadas à realização pretendida que tenham como objetivo beneficiar a população, ampliando o escopo da atividade teatral. Constata-se hoje que os grupos beneficiados com o apoio do Programa, em vigor há exatos dez anos, vêm sendo responsáveis por uma ação continuada que tem questionado as leis do mercado e se exerce na ótica de uma efetiva intervenção no tecido social.

Ao longo deste artigo nossa intenção é lançar o olhar sobre uma das modalidades mais frequentes de contrapartida propostas pelos coletivos - as oficinas - de modo a examiná-las à luz de duas categorias formuladas por Jacques Rancière, o embrutecimento e a emancipação. Paralelamente, ao pensar as oficinas coordenadas pelos grupos, levantaremos perspectivas que possam conduzir a uma conceituação específica de ação artística, passível de ser distinguida da ação cultural.

Como sabemos, a lei do Programa de Fomento foi instaurada como resultado de vigorosa batalha dos fazedores de teatro. Observa-se atualmente, no entanto que muitos grupos beneficiados tendem a contestar a necessidade de contrapartida, sob o argumento de que não caberia a eles resolver problemas sociais. Para essas pessoas, 
o compromisso com uma atuação social como retorno ao apoio público recebido seria questionável, uma vez que a realização de seu projeto artístico constituiria, por si mesmo, a contribuição mais significativa para a sociedade.

Um exame mais cuidadoso dos efeitos do Programa até o presente momento, no entanto, revela o quanto as ações realizadas na esteira de uma concepção de trabalho artístico como serviço público - na contramão dos preceitos de um Estado neoliberal - vêm sendo responsáveis por interessantes transformações no quadro das artes cênicas em nosso contexto.

Graças à proposta de contrapartidas, muitas vezes férteis e inovadoras, o teatro vem se reinventando dentro de uma ação que é simultaneamente artística e social. Diversificam-se os lugares em que ocorre o fenômeno teatral, assim como se transforma a sua distribuição na cidade. A descentralização, embora deva ser relativizada pelas proporções da megalópole, é hoje mais do que uma meta: ela constitui sem dúvida um fato tangível. Englobando esses fatores e ampliando seu significado, podemos dizer que as realizações do Programa de Fomento vêm questionando as funções da arte do ponto de vista da estética teatral.

Oficinas teatrais, da mais variada natureza, vêm sendo oferecidas pelos coletivos à guisa de contrapartida. Seu grande interesse, em princípio, seria o de disseminar a experiência do fazer teatral junto a pessoas que habitualmente não teriam acesso à expressão por meio dessa arte.

Cabe lembrar aqui que no momento em que o Programa de Fomento foi instituído a contrapartida social se inseria em uma perspectiva de articulação entre três programas municipais que se alimentavam reciprocamente: o próprio Fomento, o Núcleo Vocacional e o Programa de Formação de Público. De modo coeso, enquanto através do Fomento se apoiavam projetos de grupos estáveis e voltados para a pesquisa, no Vocacional se visava à criação de coletivos teatrais por toda a cidade, ao mesmo tempo em que no âmbito da Formação de Público, hoje extinto, se pretendia incentivar a fruição teatral, especialmente junto a escolares.

A intensa procura por oficinas teatrais é um fenômeno bem familiar aos envolvidos com a produção artística e aos responsáveis por políticas públicas no campo da cultura.

Denis Guénoun ${ }^{1}$ o destaca quando, ao discutir o relevo que o teatro possui em nossos tempos, distingue a necessidade de representar e a necessidade de olhar o que

${ }^{1} O$ teatro é necessário? São Paulo: Perspectiva, 2004. 
se representa, enfatizando o quanto a primeira tende a suplantar a segunda. Ao trazer para o primeiro plano a força do desejo de jogo no mundo atual, Guénoun questiona a postura tida como "profissional" daqueles que procuram isolar em um pretenso patamar de excelência a atuação dos que vivem do teatro, salientando que "é preciso abrir as cenas à vinda daqueles que foram delas banidos: os ditos não-atores, os não- artistas"2.

Tida pelos interessados como a modalidade que com maior acuidade permitiria a familiarização com os modos de fazer de determinado grupo, a oferta de oficinas sempre teve proeminência nas diferentes edições do Programa de Fomento. A experiência direta dos desafios da cena que ela proporciona sugere um olhar mais acurado para uma noção que, acreditamos, valeria a pena explicitar. Trata-se da noção de ação artística.

Presente na bibliografia francesa e disseminada no jargão administrativo daquele país, a ação artística se distinguiria da ação cultural na medida em que nela estaria presente a figura do artista como catalisador e revelador de questões vitais que atravessam a sociedade. Mediante as situações desestabilizadoras que constrói, o artista suscita o questionamento daquilo que pode nos parecer evidente. Assim, mais do que a perspectiva de disseminar o conhecimento do patrimônio cultural, a ação qualificada como artística daria voz a pessoas que de outro modo estariam reduzidas a se manifestarem através da voz de outros.

No bojo das ações artísticas o que se salienta é a singularidade da percepção estética presente na experiência sensível, assim como nos riscos que ela necessariamente comporta. Ao fazer arte se constrói a subjetividade, ao mesmo tempo em que simbolicamente se reconstrói um território comum.

Nessa ótica seria oportuno distinguir, como faz Teixeira Coelho em A cultura e seu contrário (São Paulo, lluminuras, 2008), a especificidade de uma ação artística em relação à ação mais amplamente tida como cultural, partindo do princípio de que a arte, em larga medida é a negação da cultura. Seu caráter divergente faz com que ela seja uma exceção em relação às manifestações da cultura, que remetem à regra. Em oposição à esfera da necessidade, a dimensão do desejo, intrínseca à atividade artística é enfaticamente salientada pelo autor como seu vetor imprescindível.

As oficinas propostas pelos projetos agraciados com o Fomento podem assim ser consideradas exemplos de modalidades de ação mais propriamente artística do que cultural, na medida em que trazem à tona essas peculiaridades.

${ }^{2}$ Idem, p. 157. 
Cabe observar que, de modo congruente com a "Declaração Universal sobre a Diversidade Cultural" publicada pela UNESCO em 2002, as oficinas, em alguma medida reconhecem a diversidade das práticas artísticas em vigor e trazem para o primeiro plano a busca de novas relações sociais. Reconhecemos entre elas atividades como a contação de histórias, o hip hop, a atuação do $D J$, o break, o grafite, os folguedos populares e assim por diante.

É nesse quadro que uma análise das oficinas propriamente ditas pode ser reveladora da relação instaurada entre as pessoas que as propõem e a população a ser beneficiada. Várias questões relevantes podem assim vir à tona, tal como a visão do fazer teatral que elas subtendem, ou a natureza dos processos de criação que elas engendram. Outro tema cuja observação pode ser pertinente é a inscrição da oficina no conjunto do projeto fomentado. Há ou não estabelecimento de vínculos diretos e recíprocos entre a oficina e o acontecimento cênico projetado pelo coletivo? Existe alguma expectativa de que os frequentadores das oficinas exerçam influência efetiva na criação?

$\mathrm{Na}$ tentativa de lançar pistas para tratar dessas inquietações, recorremos ao pensamento de Jacques Rancière, eminente filósofo contemporâneo que articula preocupações políticas, éticas e estéticas de modo especialmente instigante. Sua obra, fecunda e em contínua expansão, vem sendo gradativamente desvelada com grande interesse em meios acadêmicos brasileiros. Em seu livro perturbador " $O$ mestre ignorante"3, Jacques Rancière nos apresenta um par de categorias - o embrutecimento e a emancipação - que pode contribuir para iluminar de modo singular as interrogações acima apontadas.

Nele o autor desconcerta o leitor ao remeter à trajetória de Joseph Jacotot, homem de letras e revolucionário francês exilado na Bélgica, no início do século XIX, por ocasião da restauração da monarquia em seu país. Jacotot, o mestre ignorante viveu uma experiência que colocou radicalmente em xeque a pedagogia tradicional. Adepto convicto do ideário da revolução, ele via no ensino a tarefa de reduzir tanto quanto possível a desigualdade social, mediante a diminuição da distância entre os ignorantes e o saber. Uma vez acolhido no exílio pela Universidade de Louvain em 1818, Jacotot se vê diante do desafio de ensinar a língua francesa a estudantes que a ignoram completamente, sendo que ele próprio nada conhece do flamengo. A peculiaridade da situação o leva a lançar mão do único recurso disponível, uma edição

${ }^{3}$ Belo Horizonte, Autêntica, 2005. 
bilíngue do livro "Telêmaco" de Fénelon em francês e flamengo. O mestre solicita aos alunos que leiam sozinhos a obra e seis meses depois manifestem por escrito, em língua francesa, suas impressões sobre a leitura. Para sua surpresa os textos apresentados revelavam clareza dos enunciados e domínio da língua, sem que para isso tivesse havido uma explicação sequer de ordem gramatical que pudesse ter facilitado a tarefa dos jovens. O caminho seguido pelo mestre aponta para a confiança na capacidade intelectual de cada ser humano.

A intenção de Rancière não é a de fornecer receitas pedagógicas a partir do episódio descrito. Ao retomar essa experiência seu desejo é demonstrar que a igualdade das inteligências não é um objetivo a ser atingido, mas sim um ponto de partida, "uma suposição a ser mantida em qualquer circunstância" ${ }^{4}$ Nessa linha de raciocínio, pondera que o ato de verificar se um determinado sistema de ensino tem como pressuposto uma desigualdade a ser reduzida ou uma igualdade a ser verificada constitui uma questão política da maior relevância.

Rancière explicita as categorias que pretende destacar e que nos interessam particularmente:

Instruir pode, portanto significar duas coisas absolutamente opostas: confirmar uma incapacidade pelo próprio ato que pretende reduzí-la [embrutecimento] ou, inversamente, forçar uma capacidade que se ignora ou se denega a se reconhecer e a desenvolver todas as consequências desse reconhecimento [emancipação] .

Trata-se portanto de qualificar modos de aprendizagem a partir da relação instaurada entre mestre e discípulo; em uma delas o resultado é o embrutecimento do aprendiz, enquanto no outro caso o que ocorre é a sua emancipação.

Segundo o autor, "o que embrutece o povo não é a falta de instrução, mas a crença na inferioridade de sua inteligência"6. O princípio da explicação é tido como o próprio princípio do embrutecimento pedagógico. Assim, para ele, "o explicador tem necessidade do incapaz [...] é ele que constitui o incapaz como tal. Explicar alguma coisa a alguém, é, antes de mais nada, demonstrar-lhe que não pode compreendê-la por si só"7. Rancière vai ainda mais longe, ao destacar as relações de dependência que podem emergir e se consolidar no ato pedagógico: "Eis a virtude dos explicadores: o ser que inferiorizaram,

\footnotetext{
${ }^{4}$ Idem, p. 189.

${ }^{5}$ Idem, p. 12.

${ }^{6}$ Idem, p. 65

${ }^{7}$ Idem, p. 23.
} 
eles o amarram pelo mais sólido dos laços ao país do embrutecimento: a consciência de sua superioridade"8. E nosso autor sintetiza: "embrutecedor [é] o método que provoca no pensamento daquele que fala o sentimento de sua própria incapacidade"9.

Entre Jacotot, o mestre ignorante, e os estudantes belgas estabeleceu-se portanto uma relação fundamentada na perspectiva da emancipação dos jovens. Gerada por fatores circunstanciais, aquela experiência bem sucedida deu origem a todo um movimento de consideráveis repercussões, tendo sido na época objeto de publicações e discussões acaloradas.

Na perspectiva de Rancière - Jacotot "pode-se ensinar o que se ignora desde que se emancipe o aluno; isso é que se force o aluno a usar sua própria inteligência"10. O princípio que subjaz a essa afirmativa é o da igualdade das inteligências, axioma que conduz toda a argumentação da obra. ... não há hierarquia de capacidade intelectual. É a tomada de consciência dessa igualdade de natureza que se chama emancipação, e que abre o caminho para toda aventura no país do saber"11.

O binômio embrutecimento/emancipação parece-nos uma formulação produtiva para que possamos lançar um olhar analítico às oficinas propostas nos projetos dos grupos fomentados. Embora evidentemente a oferta de oficinas não se confunda com "instrução", como era o caso da experiência de Jacotot, as noções em pauta trazem para o primeiro plano relações de poder vigentes em processos pedagógicos e contribuem para destacar o quanto elas podem estar encobertas por representações socialmente disseminadas acerca da capacidade de quem se dispõe a aprender.

Ao tomar conhecimento de tais categorias é inevitável correlacioná-las a preconceitos solidamente ancorados - e inconfessáveis - acerca do grau de inteligência de pessoas pertencentes a segmentos menos favorecidos da população. São essas mesmas visões apriorísticas que se manifestam no âmbito da confusão presente no senso comum entre grau de inteligência por um lado e de instrução ou de escolaridade por outro.

Dentro de uma oficina artística estabelecem-se relações de ordem pedagógica. Mesmo que não sejam explicitadas, elas implicam visões peculiares sobre processos de aprendizagem, sobre a relação entre quem aprende e quem coordena e sobre o

\footnotetext{
8 Idem, p. 42.

${ }^{9}$ Jacques Rancière, Educação e Sociedade, vol. 24, nº 82, abril 2003, p. 188

${ }^{10} \mathrm{O}$ mestre ignorante, p. 34.

${ }^{11}$ Idem, p. 49. Em itálico no original.
} 
significado que ela possa adquirir no percurso dos participantes, interessados naquela manifestação artística.

Mas, mais do que isso, o teor dessas relações diz muito acerca da inscrição da oficina no âmago do projeto dos artistas. Nesse sentido, observar a existência ou não de canais comunicantes entre aquilo que ocorre dentro das oficinas e a realização artística que o grupo está construindo - espetáculo, performance, evento, pesquisa dramatúrgica ou outros - pode se configurar como critério consistente para se examinar a relevância efetiva da oficina dentro do conjunto do projeto fomentado.

$\mathrm{Na}$ grande maioria dos casos as oficinas ou workshops previstos nos projetos apoiados pelo Fomento não apresentam o caráter específico de experimentação, inerente ao próprio conceito do termo oficina. Quaisquer que sejam os temas propostos ou as pessoas a quem se dirigem - desde escolares até militantes envolvidos com ocupação de prédios - as oficinas tendem a se configurar, em última análise, como cursos. Ou seja, membros dos grupos fomentados ou artistas convidados que dominam determinado conteúdo conduzem os participantes em um processo de aprendizagem específico, que pode ser o de uma técnica - clown, commedia dell'arte, grafite - ou de aspectos de uma modalidade artística mais larga - teatro de rua, circo. O desafio que se coloca nessas circunstâncias é o da transmissão de um saber, qualquer que tenha sido a forma pela qual ele foi conquistado. Alguém que sabe ensina participantes que desejam aprender.

Em outras ocasiões, menos frequentes, as oficinas são concebidas como espaços nos quais membros dos coletivos e pessoas interessadas se dispõem, juntas, à vivência do caráter relativamente aleatório da experimentação, sem que haja um ponto de chegada previamente estabelecido. A relação pedagógica aqui estabelecida é de outro teor: não há um saber a ser transmitido, mas riscos a serem corridos juntos, interrogações partilhadas que, embora provenham da coordenação, mobilizam simultaneamente uns e outros. A assimetria das relações não implica aqui necessariamente sua hierarquia.

Assim, em 2007, o Clã Estudio das Artes Públicas organiza um workshop sobre máscaras com o artista Zigrino, para o qual convida alunos do Núcleo Vocacional envolvidos em aprendizagens em torno da comédia. De modo similar, em 2011, os membros de Opovoempé trabalham pelo estabelecimento de trocas que possam alimentar seu próprio processo criativo mediante a co-presença de artistas convidados e do público interessado em oficinas que proporcionam treinamento Suzuki e Viewpoints. 
O Ventoforte, (2002), torna possível um forte elo entre a experiência das oficinas que oferece e a criação cênica - então em processo - em torno de romances de Victor Hugo. Autores, atores, estudantes e o público em geral são convidados para experimentações partindo de personagens, situações e imagens provenientes dessas narrativas, de modo a contribuírem com invenções a serem posteriormente incorporadas à encenação.

Mais recentemente os participantes do Dolores Boca Aberta, preocupados com a coerência entre a natureza das oficinas a serem organizadas e as práticas artísticas e culturais que pautam a atuação do coletivo, se propõem a construir teatros pela cidade a partir do modelo da "arena arbórea": espaços cênicos circulares que resultam do plantio de árvores em circunferência, construídas em sistema de mutirão. Surgem assim, as oficinas nomeadas "Iniciação ao Teatro Mutirão", visando a que grupos de teatro emergentes possam se auto-gerir. Nesse caso, mais do que um conteúdo propriamente artístico o grupo privilegia a disseminação de meios que propiciem a multiplicação de fontes de criação artística a serem sustentadas de modo o mais autônomo possível: um know-how adquirido ao longo da trajetória dos responsáveis é agora compartilhado.

Não é difícil constatar nessa sequência de exemplos um continuum, cuja tendência é a de partir de uma postura mais próxima àquela de um explicador, como diria Rancière e se encaminha em direção a uma perspectiva vizinha aos valores contidos no eixo da emancipação. Transmitir implica determinado tipo de relação, enquanto o ato de experimentar junto ao outro é mobilizado por atitude de outra natureza.

Dentro dessa perspectiva, gostaríamos de trazer à tona três encenações resultantes de processos nos quais se destaca a natureza sui generis das trocas efetuadas com as pessoas que se dispuseram a partilhar o ideário dos respectivos grupos.

A primeira delas é o processo de criação de "Bastianas" pela Companhia São Jorge de Variedades ${ }^{12}$. Movidos pelo desejo artístico de trabalhar em contato com uma população específica, os membros do grupo intuem que um paradigma estético incomum poderia emergir de um processo de criação aberto ao contato direto com uma determinada comunidade.

Assim, atendendo ao convite da Secretaria Municipal de Cultura para desenvolver projeto teatral em equipamento público, a Companhia São Jorge inicia o Projeto Oficina Boracéia, em um abrigo modelo para moradores e famílias em situação de rua.

${ }^{12}$ Cf. Paula Klein, "Companhia São Jorge de Variedades. As Bastianas". Dissertação de Mestrado, ECA-USP, 2010. 
O que movia os membros do coletivo não era o desejo de promover oficina ou oferecer curso aos albergados; seu desejo era criar junto com o público para o qual a instituição se destinava, instaurando para isso a vivência cotidiana da atividade teatral dentro do albergue. Tratava-se de uma ocupação artística do local, de modo a que os residentes acompanhassem todas as etapas do processo de criação que viessem a configurar aquele trabalho da São Jorge.

Dificuldades materiais acabaram deslocando o projeto para o Abrigo Municipal do Canindé, que acolhia adultos, idosos e crianças de ambos os sexos, quase sempre desvalidos, desamparados e com sérios problemas de saúde. A aventura a ser experimentada era portanto a criação de um espetáculo a partir da interação com os residentes.

A perplexidade inicial presente em ambos os lados começa a ser superada mediante a coesão promovida pela música e pela dança, pela escuta de narrativas pessoais, pelos cortejos montados pelo grupo que visita os diferentes locais do albergue, pela participação lúdica e espontânea das crianças. Frases do texto de Gero Camilo - ponto de partida do projeto - são empregadas em diálogos travados entre as atrizes e as albergadas durante a lavagem de roupas, assim como simpatias ensinadas às atrizes são incorporadas à dramaturgia. Em suma o público da instituição se manifesta abrindo pistas para a encenação, dando opiniões e questionando a cena.

O processo de criação em seu conjunto torna-se indissociável do local e das pessoas em função das quais aquele espaço institucional foi concebido. Cuidadosamente instaurado e alimentado, o princípio de jogo se estende em seguida aos visitantes, espectadores de "Bastianas" que se deslocam até a instituição para assistir à cena gerada in loco. Uma surpreendente e perturbadora permeabilidade atravessa a relação entre albergados, artistas e espectadores; é ela que configura a potência do acontecimento proposto.

O segundo exemplo de projeto fomentado que gostaríamos de destacar é constituído por uma das vertentes do percurso que levou à encenação de "BR3" pelo Teatro da Vertigem, espetáculo premiado pela Quadrienal de Praga de 2011 como o melhor do mundo nos cinco anos anteriores.

A pesquisa em torno de um dos três "BR" que compõem a trama do espetáculo, Vila Brasilândia, procurou iluminar diferentes aspectos daquele bairro de grandes proporções através de palestras, encontros públicos com estudiosos de diversas áreas - urbanismo, filosofia, sociologia - e se desdobrou em uma série de oficinas propostas no próprio local pelos membros do grupo. 
Com a expectativa de conhecer desejos e visões de mundo de seus habitantes, cada um dos profissionais do Vertigem coordenou uma oficina específica ao longo de vários meses durante o ano de 2004; expressão corporal com idosos, cenografia, figurino, música, vídeo, interpretação, interpretação para crianças, iluminação e criação de texto foram os temas focalizados. Emergiu assim a percepção dos participantes a respeito do lugar em que viviam, os problemas locais e a história do bairro, ao mesmo tempo em que aqueles diferentes aspectos do fazer teatral eram experimentados.

Uma situação específica de aprendizado, espécie de meta-oficina completava a gama de ofertas; na expectativa de formar pessoas que pudessem dar continuidade àquela atividade após a partida do Teatro da Vertigem do local, foi proposta uma oficina de monitores. Indicados pelos coordenadores das demais oficinas já em curso, seus membros foram convidados a pensar e a propor ações para que aquele trabalho se multiplicasse ulteriormente em outras iniciativas. Preocupações artísticas e pedagógicas se fundiam de modo a impulsionar os passos a serem formulados na sequência, pela população local.

Do conjunto dessas oficinas saíram participantes que foram incorporados à encenação no Rio Tietê, conforme almejava o grupo. Cabe lembrar aqui as considerações de Guilherme Bonfanti, iluminador do Vertigem, acerca do ideário que movia o coletivo:

\footnotetext{
...o objetivo do grupo nunca foi "levar cultura à periferia" ou "fazer a nossa parte". Nossos objetivos sempre foram artísticos e os participantes das oficinas teriam conosco uma relação de aprendizagem mútua, funcionando como cocriadores do espetáculo, ao contribuírem com histórias, personagens, lugares ${ }^{13}$.
}

Estamos distantes da ótica de uma transmissão de saberes; o que se busca aqui é um processo de criação calcado na experiência da relação com os habitantes do bairro, considerada como vetor da cena. Nesse sentido, cabe observar que a densidade do trabalho já se evidencia muito antes de a encenação propriamente dita ser oferecida ao público. Ao longo dos mais de dois anos de processo que culminaram com exíguos dois meses de temporada, "BR3" já estava acontecendo e trazia consigo os frutos palpáveis de uma investigação cuidadosa, pautada por nítidas preocupações de ordem ética.

Prosseguindo nessa ordem de idéias, o último exemplo a ser destacado provém da Companhia Teatro Documentário, beneficiada com o apoio do Programa de Fomento ao Teatro entre 2010 e 2011. A partir do objetivo de examinar uma possível caracterização do teatro documentário como sendo a construção de um ponto de vista sobre

\footnotetext{
${ }^{13}$ Silvia Fernandes, Roberto Audio (orgs.) BR-3, São Paulo: Perspectiva e Editora da USP, 2006, . 95.
} 
a realidade não apoiado na ficção, o grupo concebe um projeto visando a promover o encontro com pessoas de diferentes pontos da capital paulista.

O coletivo visita outros coletivos instalados em quatro pontos da cidade - norte, sul, leste e oeste - instalando assim uma residência artística provisória em casas de grupos parceiros.

Cabe aqui abrir um parêntese para assinalar o quanto essa prática de trocas entre grupos vem sendo intensificada nas edições mais recentes do Fomento. Assim a 19ª edição apoia a Companhia de Teatro Balagan que dialoga em itinerância com sete outros grupos, a partir de sua encenação "Prometheus Nostos". A Companhia Ocamorana no Teatro Coletivo se propõe a investigar formas do agit-prop alemão e russo do início do século $\mathrm{XX}$, convidando quatro grupos para essa aventura e a Companhia Auto-retrato, ao focalizar deslocamentos urbanos, procura compartilhar sua pesquisa com outros grupos envolvidos com temas correlatos.

Voltando à investigação realizada pela Companhia Teatro Documentário, em cada uma das quatro sedes de grupos anfitriões se repete a mesma sequência: a Companhia oferece uma oficina sobre contação de histórias nas quais, vizinhos mais ou menos próximos trocam relatos orais envolvendo suas memórias. A partir desses encontros convidam-se pessoas interessadas em conceder entrevistas sobre suas histórias pessoais. O material assim levantado dá origem a uma intervenção de caráter documentário realizada pelos atores da Companhia no interior de cada uma das quatro residências onde moram aquelas mesmas pessoas e suas famílias. Transposto poeticamente, cada um dos relatos é assim restituído em forma de acontecimento cênico diante de seus autores e respectivos convidados.

$\mathrm{Na}$ fase seguinte a Companhia se instala em casa alugada no centro de São Paulo e se propõe a reunir todo o material explorado até então, de modo a elaborar uma encenação acerca das relações entre os habitantes e a metrópole. Da mesma maneira que os habitantes dos quatro pontos cardeais da cidade haviam aberto suas portas para receber os membros da Companhia, agora estes últimos acolhem o público não envolvido no processo.

Surge assim "Pretérito Perfeito", encenação documentária cuja dramaturgia é engendrada exclusivamente pelas contribuições dos depoentes, protagonizada por um deles e pelo conjunto dos atores da companhia. Fragmentados, recortados, condensados, fundidos, transpostos aqueles relatos constituem agora a própria cena. A situ- 
ação de oficina que os engendrou constitui o sentido mesmo do projeto artístico e é indissociável dele.

Os exemplos são eloquentes e ilustram uma postura distinta de qualquer visão hierárquica em torno da relação entre artistas apoiados pelo poder público e segmentos da população a serem beneficiados por esse apoio.

É a confiança no estabelecimento de uma interação fértil que desfaz visões apriorísticas sobre o outro que está no cerne desses projetos cênicos. A alteridade como fator mobilizador da produção artística é, sem dúvida, seu traço distintivo. Marcadas pela ousadia do desejo de experimentação, essas situações estão bastante próximas da perspectiva de emancipação intelectual formulada por Rancière. A verticalidade da explicação cede lugar aqui à horizontalidade do enfrentamento de desafios que dizem respeito a uns e outros.

No primeiro caso citado substitui-se o binômio ensino- aprendizagem por um processo de trocas sensíveis com uma população marcada pela miséria absoluta e pelo descaso dos semelhantes. O segundo e terceiro exemplos, por sua vez, revelam situações em que pessoas dispostas a experimentar, em alguma medida, uma aventura com o coletivo teatral em questão tornam-se co-responsáveis pelo acontecimento cênico, independentemente de qualquer julgamento vinculado à idéia de talento.

Aprendemos com Jacques Rancière que a política consiste em reconfigurar a partilha do sensível, em tornar visível aquilo que era invisível, em escutar como seres portadores de fala aqueles que eram tidos apenas como emissores de barulho. É sob essa ótica que o exame dessas realizações pode ganhar especial envergadura.

Intrinsecamente tecidas ao acontecimento cênico, as trocas com o outro, trazidas à tona por esses últimos exemplos revelam uma aventura partilhada, na qual emergem novos parceiros de criação. 